\title{
The dynamic identity construction in English as lingua franca intercultural communication: A positioning perspective
}

\section{Introduction}

In recent years, the increasing number of non-local staffs and students from different linguistic and cultural backgrounds has become a key indicator of internationalization in higher education. The continuing process of internationalization brings to the front the issue of communication in English, the unchallenged lingua franca of academia, among those whose first language is not English (Knapp, 2011). While there are established lines of research into the use of academic English in written texts, there is also an emerging body of research into the use of English as a lingua franca' (hereafter ELF) in oral discourse in academic settings (e.g., Björkman, 2008; Kirkpatrick, 2010a, 2011; Mauranen, 2006; Mauranen and Ranta, 2008). Such research has mainly focused on: 1) specific linguistic features of lingua franca communication in the academic domain; 2) comprehensibility and speakers' strategies for dealing with misunderstanding and for achieving understanding; and, 3) L1-related cultural and linguistic impacts on lecturers' and students' performance in institutionally- and contextually-defined roles. We may find that, although there has been a considerable number of studies on newly-developed international norms that facilitate ELF communication, there is insufficient research on the ways in which identities and local cultures and values are negotiated (Canagarajah, 2006b). However, as communication and identification are inseparable in ELF and ELFspecific patterns of stance-taking exist (Baumgarten and House, 2010), there is a need to go beyond the current research focus on the content of ELF interactions in order to understand how ELF speakers develop cultural affinity with a range of Englishes, and how they use English to construct or present their identities.

As part of a larger project investigating English as Lingua Franca in an Asian context (Kirkpatrick, 2010b), this paper investigates the identity construction observed in a naturally-occurring ELF conversation between three ELF users from different cultural and linguistic backgrounds at a multicultural university in Hong Kong. This study contributes to the literature by exploring how work-related ELF communication in workplaces can contribute to the sharing of cultural knowledge and the construction of a multicultural identity among the interlocutors, which may, in turn, facilitate workplace communication. The paper begins by reviewing relevant studies on ELF communications; a framework for analysing ELF communication is then outlined, before the findings are presented and discussed.

\section{Identity and power in ELF}

The term 'ELF' refers to "communication in English between speakers with different first languages” (Seidlhofer, 2005, p. 339). Research on face-to-face interactions in ELF communication has recently gained a great deal of attention, mainly in studies focused on identifying core features of ELF phonology, or on morphosyntactic phenomena, lexis and syntax (Seidlhofer, 2004). Studies have also been done to classify the phonological and grammatical features of domain-specific languages (such as ELF) in academic settings (Björkman, 2008; House, 2003; Mauranen, 2003). In line with research on the phonological and lexigrammatical features of spoken ELF interactions, studies on pragmatic intercultural communication and flexible approaches to language have 
indicated that interlocutors' pragmatic strategies may facilitate the maintenance of local English varieties (Baker, 2009). In addition, some recent studies have found that ELF users may either export their own primary culture into ELF, or re-invent their cultural identities by blending into other lingua-cultural groups (Jenkins, 2007; Li, 2009; Omoniyi, 2006; Sung, 2014; Virkkula and Nikula, 2010). Furthermore, power interplay has been found to be involved in the identity negotiation process in ELF communications (Cummins, 1996). These findings imply the necessity of addressing how ELF speakers adopt pragmatic strategies to facilitate communication, how their cultural identification impacts their language behaviours, and how they negotiate the power relations between different English varieties and the global status of different cultures to re-construct their identities and achieve local interests, in the micro-interactional context. The following paragraphs briefly review the extant studies on pragmatic strategies, identity construction and power interplay in ELF interaction.

Recent pragmatic studies of ELF have focused on the negotiation of meaning and the establishment of solidarity, with the help of shared linguistic resources (e.g., House, 2009). Knapp (2011), for example, based on date extracted from an engineering course at a German university, investigated the problems of learning and teaching via ELF; Knapp argued that, although participants from a variety of cultural backgrounds were able to successfully convey the pragmatic meaning of their utterances, they sometimes failed to choose appropriate speech acts, to negotiate forms of cooperation and to resolve conflicts. Seidlhofer (2004) argued that, in ELF communications, the pragmatic strategies interlocutors adopt to facilitate their use of local varieties also help them to maintain their own varieties, and that heterogeneity in language use can facilitate communication, contrary to the dominant linguistic assumption. It has also been found that local cultural interaction patterns influence ways of interacting in English, and that these culturespecific strategies serve to negotiate difference and ensure intelligibility (House, 2003). Moreover, according to Meierkord (2004), ELF speakers employ syntactic discourse strategies (such as segmentation and regularization) to facilitate communication, while still retaining the characteristics of their own English varieties. It is interesting to note that the language practices of members of Diaspora communities tend to shuttle between English varieties to construct new identities, in order to facilitate friendships and aid their socialization in local communities (Ibrahim, 1999; Rampton, 1995).

In recent years, the connection between identity and language use in ELF contexts has been explored. The cultural identification of interlocutors from different cultural groups may influence their language behaviours in ELF communication (LouhialaSalminen, Charles, and Kankaanranta, 2005); furthermore, a cultural 'third place' is created among ELF professionals (Planken, 2005), who establish rapport by engaging in 'safe talk' related to "interculturalness" (Planken, 2005, p. 397), including reflexive comments on their own culture and differences, to create a temporary in-group of nonnatives and share common ground.

Furthermore, Jenkins (2007, p. 43) stated that ELF interactions enable speakers' native-culture identities to "shine through"; referring to Omoniyi's (2006) identity hierarchies model, Jenkins identified 'identity-driven' as one possible factor explaining why speakers, who are well aware of native speaker norms, choose to signal a more desired identity by speaking an English variant that differs from those norms. In an empirical study involving a group of engineering students in Germany, Virkkula and 
Nikula (2010) found that access to new social and linguistic resources abroad resulted in the students adopting new identity repertories; moreover, after experienced speaking and using English abroad, the students became willing to incorporate Finnish features into their English. Reluctant to identify fully with native speaker models, the students instead constructed ELF user identities.

Some Hong Kong recent studies have investigated identity construction and the relationship between identity and accent in ELF communication (e.g., Li, 2009; Sung, 2013, 2014). Li (2009) found that participants in ELF communications must choose between speaking with a local accent (to present their Hong Kong identity) and trying to speak with a more native accent (to achieve intelligibility). Focusing on a group of undergraduate students who regularly used English in ELF contexts, Sung (2013) found that those who chose to speak English with a local accent are primarily motivated by pragmatic considerations, rather than the desire to express their lingua-cultural identity. Moreover, participants who use a more native accent in ELF settings see it as being closely related to a high level of English proficiency and conducive to their positive selfimage as a bilingual speaker. Sung (2014) further suggested that ELF communications could offer myriad identity options and provide the space for hybrid L2 linguistic practices.

The ELF speakers' transition from learner to user identity can be approached from the perspective of power, as power relations are involved in both enabling and constraining the range of identities for negotiation (Cummins, 1996). ELF contexts, in which participants can negotiate identities as lingua franca users rather than follow native speaker norms, provide new identity options and shifting power relations. According to Jenkins (2007, p. 201), "there is a second tier of power relations in ELF interactions, i.e. among ELF speakers themselves, to the extent that they see ELF varieties not as equals but as hierarchical." For example, Knapp (2011) found that some ELF speakers, such as Germans, felt more powerful than others. Moreover, power can play a major role in influencing how ELF users position themselves, both individually and collectively, and how they ascribe identities to each other (Jenkins, 2007).

In addition, researchers (e.g., Blommaert, 2005; Canagarajah, 2006a, 2006b) have stated the importance of considering how individuals negotiate the power relations in ELF communications to modify, resist and reconstruct dominant social discourses and historical contingencies, and to achieve their local interests. Jenkins (2006) and McKay (2005) found that multilingual people resist dominant community norms and achieve their personal goals by adopting convergence strategies that facilitate contact as they pursue their social and cultural objectives. According to Canagarajah (2006b, p. 204), this "localization of English" allows interlocutors to establish interpersonal norms suitable for each interactional context.

\section{Theoretical framework: positioning theory and discourse analysis}

From a postmodern perspective, language both represents and creates one's social reality (Wood and Kroger, 2000). Positioning theory (Davies and Harré, 1990; van Langenhove and Harré, 1999) examined how the construction of social reality and (of particular interest to this study) identity and power are accomplished through interactions. Harré and Moghaddam (2003, p. 6) argued that, in every social milieu, there exist multiple subject positions that "people can adopt, strive to locate themselves in, be 
pushed into, be displaced from or be refused access.” As such, in conversations, individuals can position themselves or others, can resist being positioned, or can reposition themselves, either deliberately or unintentionally. Therefore, rather than rely on static roles to describe how individuals act, positioning theory states that the dynamic and changeable aspects of social life can be brought forth through discourses that offer subject positions individuals can either take up or be forced into (Brinkmann, 2010). The notion of personal agency, which is relevant to how individuals make choices in institutional discourses, is central to positioning theory.

Positioning theory offers a toolbox that facilitates the understanding of the ways in which people do things, and the meanings and normatives ascribed to what they do. Harré and Moghaddam (2003) proposed a positioning triangle of (1) position, (2) storyline, and (3) acts. Positions are groupings of beliefs about how rights and duties are distributed in the course of a personal interaction episode and the taken-for-granted practices through which most of these beliefs are realized (Harré, Moghaddam, Cairnie, Rothbart, and Sabat, 2009). In every social context, there exists a realm of positions in which people are positioned morally, responsibility is ascribed and 'oughts' are involved (Harré and van Langenhove, 1999).

van Langenhove and Harré (1999) outlined three forms of positioning: selfpositioning; forced self-positioning; and, the deliberate positioning of others. Selfpositioning occurs when one attempts to express one's agency to achieve a particular goal in their discursive practice. In forced self-positioning, individuals position themselves as they believe they are required to by either the social discourse or their interlocutors. The deliberate positioning of others involves intentional positioning oneself in a manner calculated to impel someone else to adopt a particular position in response.

Drawing on positioning theory, this study investigates how, in ELF communication, interlocutors position others, resist being positioned by others, and reposition themselves. Positioning theory enables us to examine the interlocutors' identity formation process within a positioning act episode, and to investigate how cultural resources and repertoires shape individuals' positioning acts and how various facets of individuals' positions are oriented across multiple, interrelated contexts and perceived social boundaries (Anderson, 2009). Positioning can be seen as a constitutive form of mediation that includes micro-, meso-, and macro-level activity, and that links immediate social interactions to larger social structures. Based on the theoretical framework discussed in this section, this study addresses the following question: 'How are the identities of ELF speakers actively constructed in a single ELF interaction at a multicultural university in Hong Kong?'

\section{Method}

The data for the analysis are drawn from a corpus collected for a larger project examining English language use among English speakers in an Asian contextspecifically, the Asian Corpus of English (ACE) positioned in the outer and expanding circles of (World) Englishes (Kachru, 1992) (see Kirkpatrick, 2010b). This one-millionword corpus is composed of hundreds of naturally occurring speech events in different contexts - educational, science, business and social. The data were recorded in countries and territories across Asia, including China, Hong Kong, Taiwan, Japan, the Philippines, Malaysia, Vietnam, Cambodia, Thailand, Singapore and Brunei. Participants were selected for the study based on their having self-identified as having an Asian first 
language (L1) and having English as an additional language. Potential participants were approached in a neutral environment and given a permission sheet inviting them to participate in the study; those who participated were allowed to withdraw at any time. In the event, none of those who agreed to take part withdrew from the study; however, had they done so, all recordings and records of their participation would have been destroyed.

This study investigated how work-related ELF communications in educational settings can contribute to knowledge sharing and identity construction. After scanning the relevant data, one interaction between one librarian and two academic staff members in a tertiary education institution (involving such relevant issues as identity, culture and knowledge sharing) was chosen for closer study; the entire 50-minute interaction was conducted in English. The data analysis presents a rich picture of power interplay, the negotiation of institutional roles and subject positions, and the establishment of alignment.. It is important to note that, since the focus of this research is on workplace ELF communication in educational settings, the data analysis and discussion are closely related to these issues, and no generalization to ELF communications in other contexts will be made.

The observed interaction bean as a presentation on or introduction to the library's eservices; as such, S1 took a commanding role. S1 is a Hong Kong Chinese male librarian whose first language is Cantonese, and who also speaks English. S2 is a Singaporean Chinese male academic whose first language is Hokkien, and who also speaks both English and Mandarin. S3 is a British female academic whose first language is Bengali, and who also speaks Hindi and English. All the interlocutors resided in Hong Kong when the data was collected, in 2010.

The recording was transcribed according to ACE protocols (which closely mirror the Vienna Oxford International Corpus of English) using VoiceScribe software (see appendix). In order to accurately portray the interlocutors' true utterances, no adjustments were made to their original speech and the transcript includes flawed grammar, false starts, hesitations and breathing. The transcript was checked by a second researcher for accuracy.

Data analysis occurred in a recursive, iterative manner, moving back and forth between the data and the theoretical framework described above. According to Bogden and Biklen (2003), data analysis reflects the theoretical approach adopted by a study - in this case, positioning theory. Some "indigenous concepts" (Patton, 2002, p. 454) employed by the interlocutors when negotiating their positions (e.g., "standard English", "linguistic imperialism", "American accent", "British accent", "monolingual", "multilingual", "overseas experiences", "educated locally") were identified. The interrelationships among these concepts were established, and theoretical categories with the potential to address the research questions gradually emerged, including "negotiating institutional roles in ELF communication", "negotiation of identity", "shifting subject positions", and "establishing alignment". The analysis of data extracts relating to the above four categories was informed by positioning theory to gain insights into the linguistic practices in ELF interactions, to explore the ways in which the interlocutors positioned themselves and others, and to determine how they responded to being positioned by others. An analysis was also conducted to understand the role played by the ELF speakers' linguistic and cultural backgrounds, histories and English varieties (assigned with some pre-existing values) in the positioning and being positioned process. 


\section{Findings}

\section{Negotiating institutional roles in ELF communication}

At the beginning of the conversation, the librarian (S1) assumes an instructional role, introducing the two academic staff to a new database; in doing so, he attempts to establish a legitimate and authoritative identity as an expert in library use. His authority is challenged by one academic staff member (S2), who displays his own expertise and establishes his identity as a professional in English language and literature education. The following extract shows how the three ELF speakers negotiate the institutional roles by re-establishing new storylines.

\section{Extract one}

$1 \mathrm{~S} 1:<7>$ those with $</ 7>$ this er: $\log 0<8>$ maybe have such kind of features okay $</ 8>$ you can (.) you can even er listen to this (.) articles

2 S3: $<8>$ oh there's a logo okay hm $</ 8>$ oh:

3 S1: just click on the listen then you connect to the server but it take times okay wait connect to the media and then you can just er (.) <un> out for you

4 S3: oh

5 S1: and also you get the features of translate $<9>$ I have shown you $</ 9>$

6 S2: $<9>$ it's good for $</ 9>$ kids to practice reading $<1>$ aloud $</ 1>$

7 S3: $<1>@</ 1>$ yeah: yeah

8 S1: yeah it takes time

9 S2: but it doesn't this doesn't happen (.) to every articles you know

10 S1: yeah

11 S2: yeah

12 S1: yeah $<2>$ not for $</ 2>$ every

13 S2: $<2>$ I see $</ 2>$ like usually the longer more important articles that I want (.) I usually have to read online (.) because I tried printing it out it turned out to be very small font and so difficult to read

14 S3: hm

15 S1: yeah you just get the image of the just like newspaper in front of you

16 S3: hm:

17 S1: you just flip it and you can hear it

18 S3: that's hm

19 S2: what accent is that I'd be interested to know

20 S3: <5>@@</5>

21 S1: it's machine I think

22 S2: so British or American

23 S1: it's okay

24 S3: American

25 S2: American

26 S1: American

27ff S3: yeah (.) American

S1's self-positioning begins with an introduction of how to use the database. He uses a series of imperatives to guide S2 and S3 and constructs an identity as an expert on searching and using different database functions. In turn 6, however, S2 emphasizes that the interface is more suitable for young children and, by doing so, distances himself, as an academic, from the utility of the database. In the process, he denigrates the value of S1's work. In turns 15 and 17, S1 tries to show another characteristic of the database by presenting a newspaper-like image, intentionally re-establishing the database's relevance to S2 and S3. In turn 19, S2 asks the identity of the accent with which the English is spoken in the recording; we may construe this as a deliberate challenge to S1's authority, 
because S2 - as an English language teacher educator - should have been well able to identify different English accents, as reflected in turn 25. Responding to S2's question ("what accent is that I'd be interested to know") S1 offers an irrelevant answer ("it's machine I think"). Realizing S1's lack of knowledge in this field, S2 poses another question ("so British or American"), again getting no useful response from S1 ("it's okay"). The correct answer is provided by S3 in turn 24, confirmed by S2 in turn 25, agreed to by S1 in turn 26 and re-affirmed by S3 in turn 27. Within this process, we see S2's deliberate positioning of others in an effort to challenge S1's dominant role; S2's self-positioning to change his identity from that of a database operation layman to that of a language expert; and, S1's forced positioning when he has to admit the legitimacy of S2's and S3's positions in the field of language (van Langenhove and Harré, 1999).

\section{Negotiation of identity}

In addition to institutional roles, personal history, values and expertise in different areas are utilized in the identity negotiation and renegotiation process, as reflected in the following extract.

\section{Extract two}

1 S1: that can also show yeah this is very interesting features and if you select them for example French one gradually get can translate for you

2 S3: hmm

3 S1: the English they use is very standard $<3>$ either American or British $<8>$ not the non-standard English like Singapore <@> sorry I don't mean that but Hong Kong people like the standard English $<8>$ well I think people from the whole world as well more opportunities if you can speak standard English@

4 S2: I really hope there'd be a day where spoken English is not spoken with like American or British accent or dominated by British or American accent really

5 S3: yeah

6 S2: it is a narrow view towards English learning $<7>$ linguistic imperialism

7 S1: okay for that's the website for

8 S3: global

9 S2: like a very hh a neutral kind of global accent because I get really really upset about people's prejudice on different Englishes

10 S3: $<8>$ I think that's like $</ 8>$ the default

11 S1: yeah default

12 S2: yeah

13 S3: American accent right I mean that's like in America people would say to me oh you don't have an accent by which they mean I have an $<$ @ $>$ American $<9>$ accent

14 S2: yeah, when I was teaching in Australia $<8>$ I found a lot of people even so-called native speakers $<5>$ learn not to rank varieties of English $</ 9>$ it is like when you have more chances to learn what others are thinking $\mathrm{xxx}$ to go to different places (.) you become more tolerant

15 S1: okay (.) so even I cannot read French <un> xxx just chose to translate it and hope it works English (.) and (.) < smacks lips > doesn't make sense

16 S3: so translates

In turn 3, S1 portrays American and British English as 'standard' English and marginalizes other Englishes, including the Singapore and Indian varieties spoken by S2 and S3, respectively. S1 also draws on the language ideology of Hong Kong society, which values American and British English and utilizes 'rationalization' as a 
legitimization strategy ${ }^{1}$ to link having a 'standard' English accent to career opportunities. Also in turn 3, S1 further extends this recognition of 'standard' English to include the entire world. S1's position is challenged by S2 and S3 through authorization (Fairclough, 2003), when they refer to the concept of linguistic imperialism (Phillipson, 1992) and position themselves as experts in the field of English language education. In turn 14, S2 draws on his personal and professional experiences to consolidate his views and to position S1 as someone who has had little international exposure; in the process, a global identity with "a kind of neutral accent" is constructed.

Personal agency emerges in the exchanges as well. S1, facing a disadvantageous situation, changes the topic (in turn 15) to the functional use of the database. He utilizes local identity and local value to position his subject in the conversation, effectively valuing the prestige of British and American English, and implicitly downplaying that of the accents of S2 (Singaporean English) and S3 (Indian English).

\section{Shifting subject positions}

Shifting subject positions can be seen in the conversation. Although, in extract two, S2 asserts the equality of different varieties of English, in extract three he displays a separate multilingualism ideology that places native-like proficiency in English in opposition to being biliterate in English and Chinese.

\section{Extract three}

1 S3: $<6>$ so is this how you'll keep up with

2 S1: yeah

3 S3: [Singapore] $<7>$ [first name1 ] $</ 7>$ \{question is addressed to S2 but S1 thinks it's addressed to him\}

4 S1: $<7>$ yeah if you like to read the [place1] $<$ un $>\mathrm{xxx}<$ un $>$ you can select by (.) $<$ slow $>$ country

5 S2: but I don't do it on a daily basis I usually do it like once a week

6 S1: uhuh $<8>$ got to [Singapore] $</ 8>$

7 S2: $<8><$ un $>\operatorname{xxxxx}</$ un $>$

8 S3: uhuh

(1)

9 S1: and you get I- it also include some Chinese as well $<$ 9 $>$ in the $<$ un $>$ xxxx $</$ un $></ 9>$

10 S3: $<9>$ right

11 S2: I can't read Chinese

12 S1: you cannot read Chinese oh really

13 S2: English is my native language

14 S1: oh so you are not multilingual

15 S2: @@in Singapore English is the official language and everyone can speak English well $<5>$ but Chinese and other minority languages kind of belong to the secondary languages

16 S1: you know in Hong Kong er: we need to use English Putonghua and Cantonese

17 S2: maybe that's why the English level of Hong Kong people are declining

18 S1: multilingualism, how about d- do you know Hindi@@

19 S3: er: do they have $<1>$ oh they have there $</ 1>$

1. Legitimization strategies include authorization, which involves referring to "the authority of tradition, custom, law, and of persons in whom some kind of institutional authority is vested", rationalization, which involves referring to "the utility of institutionalized action, and to the knowledge society has constructed to endow them with cognitive validity", and moral evaluation, which involves referring to value systems (Fairclough, 2003, p. 98). These strategies play important roles, both in establishing and cultivating belief systems and in justifying the elements related to social structures. 
$20 \mathrm{~S} 1:<1>$ they have [place2] $</ 1>$ of this is the (.) newspaper (something) (.) [place2]

21 S3: o:kay

22 S1: you can read

23 S3: yeah

24 S1: so it support multi languages

25 S3: uhuh

26 S1: you can just click on this and

27 S3: it's very cool

27 S3: It's very cool.

In turn 9, S1 introduces the database's multilingual function to S2 and S3, whom he sees as multilingual speakers. In turns 11 to 18, multilingualism and 'native' proficiency are negotiated. Despite his earlier appeal for a neutral, global English accent and equality among the different varieties of English, and against the ideologically dominant position of American and British English accents, S2 establishes, in turn 13, a correlative linkage between 'native' English proficiency and monolingualism. He contradicts his earlier flexible views on multilingualism (i.e., his support for the legitimacy of 'native' accent(s)) by describing English as his 'native' language and excluding Chinese from his literacy repertoire. In turn 15, S2 emphasizes that English, as Singapore's official language, is prestigious, while Chinese and other minority languages are "secondary". In turn 17, responding to S1's comment that Hong Kong people need to speak three languages, S2 links that multilingualism to their purportedly declining English proficiency. A separate bi/multilingualism ideology seems to be inherent in S2's argument, i.e., bi/multilingualism implies non-native-like proficiency in English, which contradicts his earlier flexible view on English varieties.

In turn 18, S1 tries to change the topic back to the database in an effort to reestablish his institutional position, and seeks S3's support by introducing her to its Hindi version (S3's heritage language). In turns 22, 24 and 26, S1 draws on S3's multilingual background to re-establish the utility of the database.

\section{Establishing alignment}

The interlocutors experienced a process through which they achieved alignment. In the following extract, S1, the librarian, tries to introduce the database's citation searching function. In the ensuing process, the interlocutors' positions are negotiated, re-negotiated and mutually-constructed in relation to expertise knowledge, personal history and culturally conditioned norms (Anderson, 2009).

\section{Extract four}

1S2: @@ like is there anyway can you show us like how to find out if people are citing you (.) citing my, our work

2 S1: okay

3 S2: yeah can you show us

4 S1: yep use the <soft $>$ database $</$ soft $>$ (.) not all the database support such er such kind of er citation searching hh er one of which is the s- scopus \{types\} SCOPUS (.) this one scopus it's a large database

5 S2: larger $<2><$ un $>$ xxxx $</$ un $></ 2>$

$6 \mathrm{~S} 1:<2>$ it's a very very $</ 2>$ large database it's a hh it's including \{coughs\} multi disciplinairy social science science health science (.) humantities $<3>$ as well $</ 3>$

7 S2: can search $<4>$ search mine $</ 4>$ can search mine

$8 \mathrm{~S} 1:<4><$ un $>\mathrm{xxx}</$ un $></ 4>$ types $\}$ you $<5>$ have a particular search term $</ 5>$ 
9 S2: $<5><$ un $>\operatorname{xxxxxx}</$ un $></ 5><6>$ yeah $</ 6>$ [first name1] [last name1]

10 S3: $<6>@ @</ 6>$

11 S1: [first name1] [last name1]

12 S3: it wouldn't be author would it

13 S2: \{S2 spells out his first name which has five letters followed by second name which has three letters $\}$

14 S1: \{types S2's first and last name\}

15 S2: \{clarifies the spelling of his last name by spelling it out again\}

16 S1: \{types for three seconds\} (10) it's in: (.) some science field (.) medicines (.) engineering (.) subject areas maybe

(4)

17 S2: <fast $>$ well you should type out $</$ fast $>$ the full name so it's easier to search

18 S1: maybe do you have any er

19 S2: \{spells out first name\}

20 S1: and it just support $<7>$ initial $</ 7>$ hh you have er a title and a keyword title title keyword or

21 S2: $<7>$ [last name2] $</ 7>$ or just put Singapore

22 S1: Singapore

23 S2: yeah

24 S1: \{types\} or maybe I I show I show you the the er the president's journal

25 S2: yeah anyway

26 S1: [first name3] [last name2] \{types $\}$ show you his \{clicks mouse for 4 seconds $<<$ slow $>$ [first name3] [last name2] $</$ slow $>$ oh it should be $<$ spel $>$ a p l $<$ /spel $>$ in this format $<$ spel $>$ a p l $<$ spel $>$

27 S3: but this is the like searching (.) by author (.) right

28 S1: $<8>$ yeah $</ 8>$

29 S3: $<8>$ but $</ 8>$ that's not what you're asking you're asking for

30 S1: you have to search that particular art- article first

31 S2: oh $<9>$ you $</ 9>$

$32 \mathrm{~S} 1:<9>$ then you can $</ 9>$ show the site by

33 S2: o:kay

34 S1: okay (.) $<1>$ so $</ 1>$

35 S3: $<1>$ er $</ 1>$ okay

36 S1: so it's all the article's by president [last name2] (.) so

37 S3: can then it will tell you

S2 asks S1, in turn 1, how to find citations of their works. Through the words "my, our works", S2, to a certain extent, self-positions his academic identity in the conversation. Rather than directly demonstrating how to search for article citations, S1 introduces the database and distinguishes it from other databases, in turn 4. This may be understood as an attempt to position himself as an expert in using the database. In turn 7, S2 pushes him to search his works, practicing his own agency on a topic relevant to his academic identity. Although (in turn 8) S1 suggests using “a particular search term”, S2 insists on inputting his own name (turn 9). The doubt S3 raises in turn 12 ("It wouldn't be author, would it?”) is ignored by S2. S2 then refuses to accept S1's suggestion that he specify the subject area to facilitate his search (turn 16), insisting instead that S1 input his own full name. In the above turns, we can see that S2 gradually re-positions himself from information seeker to information provider, to some extent. In turn 20, S1 indicates that the system may only support initials, and that a keyword may be needed. S2 asks S1 to input his country of origin, Singapore, in an alignment establishing behaviour (turn 21). S1 then changes the idea and suggests that he search the president's articles first, in turn 24. This could be an attempt to re-gain the leading role and re-build his authoritative position in the conversation. In turn 25, S2 agrees to cooperate, though reluctantly. 


\section{Extract five}

1 S1: yeah you can $<2>$ click on $</ 2>$ this articles have been cited (.) eleven times in this database

2 S3: $<2>$ okay $</ 2>$ oh:

3 S1: they even want to know who are citing you just click on the $<$ un $>$ (.) just

4 S2: hm

5 S1: eleven

6 S3: and $<3><$ un $>\mathrm{xx}</ \mathrm{un}></ 3>$

$7 \mathrm{~S} 1:<3>$ you get $</ 3>$ all (.) all your friends @ (.) some you know that oh they are using your articles (.) okay (.) this database also allows you citation <smacks lips> a hundred (.) once you you have to log-in and then register for an account then afterwards (.) if there is anybody citing your article

8 S3: you $<4>$ can ge $t</ 4>$

9 S1: $<4>$ then you'll $</ 4>$ get the get the email (.) oh somebody's using your articles

$10 \mathrm{~S} 3: \mathrm{hm}$

$11 \mathrm{~S} 1$ : this is this is one database which supports such kind of citation counting hh there's another one $<$ un $>$ citation index $(2)<$ un $>$ xxxx $</$ un $>($.) two biggest $<5>$ one $</ 5>$

12 S2: $<5>$ you $</ 5>$ can pick up my articles

13 S1: yeah I try

14 S2: =can't pick up my articles (.) how to know who (.) are the people citing me

15 S1: okay (.) social science citation index \{clicks and types for 10 seconds\} \{spells out the letters of the family name of S2 followed by the letters of the first name $\}$ er: $<$ un $>\operatorname{xxxx}</$ un $>$ Singapore ?

16 S2: yeah

\{S1 continues to type for 10 seconds\}

17 S3: keyword right

18 S1: yep

19 S3: hm

20 S1: $<$ un $>\operatorname{xxxx}</$ un $>(8)<$ fast $>$ is it this one $</$ fast $>($.) this $<6>$ higher $</ 6>$ education $<$ un $>\mathrm{xxx}$ $</$ un $>$ hh and and this one get one (.) this this articles has has been cited on:c:e \{emphasis on one $\}$ this is a (.) two thousand and two thousand and two hh (.) so (.) your article has been cited by (.) this one this is yours $<7><$ un $>\mathrm{xxxx}</ \mathrm{un}></ 7>$

21 S2: $<6>$ yeah $</ 6>$

22 S3: $<7>$ by you $</ 7><8>@<</ 8><9>$ @@@@</9>

23 S2: $<8>$ by myself $</ 8>$

24 S1: $<9>$ by yourself okay so you liked it $</ 9>$ you know the relation (.) okay

(2)

25 S2: it doesn't really pick up so this is not very useful (.) i think the other one is better (.) scholar dot Google dot com (.) that one picks up all of

26 S1: yeah because $<1>$ this database $</ 1>$ focus on the social science

27 S2: citations

28 S3: yeah right

In turn 1, S1 reports that one colleague's article has been cited 11 times, and continues to take a leading role by introducing the database's citation searching function (in turns 3, 7 and 11). When S2 again asks that articles be searched (in turn 12), S1 acquiesces, and finds that one article had been cited only once (by S2 himself); to avoid losing face, S2 immediately challenges the effectiveness of the database. S1 sounds supportive (turn 26), as does S3 (turn 28); the following extract shows their joint effort to weaken the negative impact of the citation search on S2's academic identity, which is drawn upon to establish his dominant position in the conversation.

\section{$\underline{\text { Extract six }}$}

1 S1: actually all this citation database focus on the social science because science and social science may used to count $<2>$ as kind of citations er is in the $</ 2>$ quantify the research but for the humanities field arts and humanities fields citation is not so: important 2 S3: right 
3 S1: yeah

4 S3: that's true

5 S1: and (.) hh er for the arts and humanities most publication in in the book form monograph format (.) yeah most scholars they write books rather than hh just write their articles (.) yes (.) so this is an different between the

6 S3: hm

7 S1: characteristics of the discipline

8 S3: hm (4) it's true

9 S1: so you see the even in prof- president [last name2]'s articles er c- it's cite because he works in the social science $()<3>$. social sciences area so that $</ 3>$ so it's picks more (2) articles hh for the languages or humanities then (.) less journals are included in the database

10 S3: $<3>$ yeah it sort of picks up more $</ 3>\mathrm{mhm}$

$11 \mathrm{~S} 1$ : so you see the pool is smaller (.) so you you know the potential citation will be is (.) will become small as well

12 S3: right $<$ soft $>$ right (.) right (.) hm $<$ soft $>$

13 S1: well, I never think the citation should be regarded as the tool for evaluating the quality and importance of an academic publication. I don't quite agree with the general practice in the academic world

14 S1: <soft> good any things you want to know more

15 S3: <slow $>$ n:o $<$ slow $>$

16 S1: and you know about our research repository

17 S2: yeah this is useful

It is interesting to note that only S1 and S3 participate in the conversation in turns 1 to 16 , as they try to ameliorate S2's disadvantageous position. In turns 1, 5 and 9, S1 differentiates between the social sciences and the humanities in terms of publication types, and attributes the low citation rate of S2's article to the area in which his work had been published. S1 makes justifications based on his expertise and implies that the citation rate of S2's works is not a reflection of its quality or impact; in turn 11, he then uses a metaphor to reinforce this justification. In turn 13, S1 dismisses the general academic practice of using citation rates to gauge the importance and impact of research works, with the apparent support of S3. In turn 16, S1 changes the topic to the research repository, eliciting S2's response, in turn 17, that “this is useful”. The interlocutors' rapport having thus been re-established, S3 returns to the database's multilingual support.

\section{Extract seven}

1S1: yeah this is useful

2 S3: yeah the database is good er (.) $<\mathrm{un}>\mathrm{xxx}</ \mathrm{un}>$ citation search er: support of different languages

3 S2: yeah $<2>$ when I have time I can pick up my French

4 S1: you know French

5 S2: yeah hm </8> I learnt in college er: and Spanish

6 S3: see you are multilingual also speak $<9>$ Mandarin right

7 S2: yeah $</ 5>$ right you as well English Urdu?

8 S3: also my hometown dialect $</ 2>$ and you?

9 S1: like most Hong Kong people Cantonese English and Putonghua

10 S2: English is the only shared language of us

11 S1: $<9>$ but there are different cultures (.) we are in a multicultural world you know we are multicultural people

12 S3: multicultural $<5>$ right

13 S2: yeah

In turn 2, perhaps to compensate for the face-threatening act shown in exact three, S3 tries to reframe the database's multilingual support as an advantage. Interestingly, 
contrary to his language behaviour in extract three, S2 agrees and links the function of the database to his personal plan for re-learning French (turn 3), thus rationalizing the usefulness of the database. In the ensuing turns, the interlocutors' common features are identified-i.e., being multilingual and having English as their shared language. In turn 11, an in-group multicultural identity emerges from S1's comment and is supported by his interlocutors.

Extracts four through seven are consecutive, and have only been separated for convenient analysis. We can see that the interlocutors use different institutional roles to negotiate their positions and identities in the four abstracts, and employ their background knowledge, values and understanding of the social discourse to achieve alignment in the conversation through self- and other-positioning (van Langenhove and Harré, 1999).

\section{Discussion}

This study has investigated the identity issues contained in a single ELF interaction at a multilingual university, involving three interlocutors with different cultural and linguistic backgrounds, English being the only language they share. In this study, positioning theory has enabled us to explore the subject positions ELF users can "adopt, strive to locate themselves in, be pushed into, be displaced from or be refused access [to]" (Harré and Moghaddam, 2003, p. 6) through language practices shaped by their historical and cultural backgrounds and by social discourses. Highlighting duties, the meanings of actions and the idea that people are characters in storylines, positioning theory allows for a dynamic, evanescent and mutually constitutive perspective on ELF communication.

In the conversation, the librarian (S1) initially positions himself as an information provider, taking up an institutional role by demonstrating a new database to the teaching staff and familiarizing them with it. However, his authority is challenged and the utility of the database questioned by an academic staff member (S2). Following a critical facethreatening moment, the participants turn difference to congruence, and construct an ingroup identity. It is noteworthy that the multilingual ELF users in this conversation reach alignment through difference and establish a commonality based on their all being multilingual and multicultural. They each draw on their own institutional roles, histories, memories and language(s) to construct and negotiate identity in their cross-cultural communications.

The findings show that the ELF participants' institutional roles are culturally determined, and are not fixed but vary in different phases of the discourse (Knapp, 2011). In the discourse of introducing the library's services, in which S1 assumes a leading role as an information provider, the ELF interlocutors' cultural, linguistic and knowledge repertoires contribute to the negotiation of their communicative rights and obligations, as well as to the structure of the discourse as a whole. In other words, in this ELF conversation, ascribed responsibility and thoughts shift due to the interlocutors' different values and norms. For instance, in extract one, when S1 attempts to play an institutional role, S2 displays his own English language and literature education expertise by challenging S1's knowledge of English accents. S1's identity as a non-academic with limited knowledge in the field and limited understanding of English varieties is otherpositioned in the exchanges initiated by S2, who positions himself as an academic with international exposure. S2 thus takes over the role of information provider from S1. 
Furthermore, by drawing on his own expertise and experience to question the utility of the database, S2 devalues S1's responsibilities.

The findings in this study suggest that both identity and power interplay are involved in ELF communications, and that the macro linguistic context (in this case, the context of Hong Kong) also plays a role in constructing identity and negotiating power relations in ELF conversations. In extract two, for example, to counter his devalued position, S1, a Hong Kong native, voices the prevalent Hong Kong view that only American- or British-accented English can be considered standard English, implicitly marginalizing other varieties, including the Singaporean and Indian Englishes spoken by S2 and S3, respectively, thus challenging their identities as experts. S2 subsequently references his overseas working experience and his knowledge of research findings to argue for an equal position for his and other English accents and varieties, and introduces the notion of global accent and identity. S2 re-establishes his academic identity and otherizes S1 as non-academic; the power relations between the two are thus regulated.

Interestingly, in extract three, S2 criticises the multilingualism advocated in Hong Kong (blaming it for the decline in English proficiency among Hong Kong people), in strong contrast to his positive view of the dominant status of English in Singapore. These findings show that the micro-linguistic context plays a unique role in shaping interlocutors' self- and other-positioning through power negotiation in ELF communications. In other cultural and linguistic settings, ELF interlocutors may act differently due to differences in language ideologies, social discourses, English proficiency levels, histories, and the interlocutors' cultural memories. A deeper understanding of the influences of the broader sociocultural and linguistic context on ELF communications is necessary, due to the increasing number of people involved in ELF interactions globally.

As mentioned above, contradictions in identity formation exist in ELF communication. To gain an advantageous position in their interactions, the interlocutors display different language ideologies at different phases of the discourse. For example, S2 displays a flexible ideology towards English varieties in extract two, but a more rigid separate language ideology in extract three. The database's multi-language support function, emphasized by S1, is devalued by S2, who claims that Chinese is not part of his linguistic repertoire, and that it would be more effective to learn language in a monolingual context. As suggested by Linehan and McCarthy (2000), positions in microinteractional moments are determined by how they are talked into being and by members' ideologies and cultural resources; the shifting nature of and contradictions inherent in identity construction can also occur in a monolingual or monocultural constellation. However, there is some indication that the interlocutors' diversified cultural and linguistic resources have some impact on the negotiation of identity and power relations in ELF interaction. Evidence of how immediate ELF communication might be influenced by the broader social discourse can be found in S2's attempt to place the language policies of Singapore and Hong Kong in opposition, and to link his native proficiency to Singapore's monolingual policy.

Alptekin (2010) argued that ELF users don't necessarily have prior knowledge of their interlocutors' norms, and that there is thus no authority on the language being used. This study suggests that the interlocutors move beyond language use in specific interactional contexts, and draw on their own histories and cultural knowledge to define 
and re-define the different positions of English language varieties in a broader context, so as to position their own English varieties at a privileged or advantageous position in the micro-interactional context (van Langenhove and Harré, 1999). By adopting an intercultural teaching approach, teachers teaching English as a second/foreign language (L2), as ELF users, can position themselves as legitimate speakers of English, help students to develop a pragmatic awareness of the potential difficulties in cross-cultural interactions, and enable them to develop strategies to negotiate these differences successfully (Davies, 2004), such as seeking clarification, establishing rapport and minimising cultural differences (McKay, 2002).

ELF users may experience the process of activating and establishing mutually recognized sets of attitudes, forms and conventions that facilitate successful communication (Canagarajah, 2007). It is interesting that, despite the subtle power relations negotiations they undertake and the authoritative positions they assume, the ELF speakers in this study pursue alignment when a face-threatening episode occurs. In doing so, they appear to take into consideration their interlocutors' histories, values and cultures, and to draw upon their own culturally conditioned norms to gradually foster smooth socialization.

The findings indicate that ELF communication provides a context in which interlocutors construct a multicultural identity (Brutt-Griffler, 2002) and develop an awareness of each other's variety of English. Multilingualism and multiculturalism are at the centre of ELF's hybrid community identity and speaker proficiency (Canagarajah, 2007). The findings reflect that, when ELF users practice their culturally-laden linguistic behaviours (Louhiala-Salminen, Charles, and Kankaanranta, 2005), they experience both positioning and being positioned in the ongoing communications. There seems to exist a dynamic interplay between legitimacy, illegitimacy, marginality and authority of language varieties, and a negotiation between flexible and rigid views of language learning and use. The participants move from antagonism towards, to sharing knowledge about and showing appreciation for their interlocutors' cultures and languages. By bringing with them culture-specific strategies that facilitate negotiation, the ELF users in this study learn to take a fluid attitude towards language boundaries and identities, and to balance distinctive features of identity with the needs of collaborative communication (Khubchandani, 1997; Planken, 2005). Furthermore, they provide reflective comments on their own culture, and balance intragroup solidarity with intergroup harmony by creating a temporary in-group multicultural identity.

The analytical approach this study has adopted - that is, discourse analysis within a positioning theoretical framework (van Langenhove and Harré, 1999) - has pedagogical implications. Training in such areas as textual or conversation analysis would enable students to avoid simplistic interpretations when reading ELF texts and interacting with other people through ELF.

Moreover, the three forms of positioning are relevant to classroom teaching practices. Teachers' self-positioning, for instance, helps to explain how they position themselves in the classroom. While some teachers see themselves as transmitting knowledge of 'standard' English, others may view their role as offering learners exposure to English as a global language as well as to the different cultures; the teachers' positioning guides their interactions with classroom learners. Teachers can also intentionally or unintentionally position students in more positive or more negative ways 
through their pedagogical approaches, which, in turn, may influence students' selfpositioning. While seeing students' 'non-standard' English accent as deficient may marginalize them in the ESL/EFL classroom, an intercultural approach can allow the students space to negotiate, analyze, and reflect on the socio-cultural aspects of intercultural communication and secure intercultural understanding.

\section{Conclusion}

In the context of ELF communication, tensions exist between ideologies, values, social problems and practices, as well as between different communities. ELF communication provides a context in which interlocutors can see themselves through the lens of their embodied history and subjectivity and that of others, and create new relationships and identities. The negotiation of power relations between different English varieties, and of the global status of different cultures, contributes to identity construction and the regulation of institutional roles and duties in the micro-interactional context.

The data on which this study draws were extracted from the one-million-word Asian Corpus of English. The data was somewhat limited and a longitudinal perspective could be taken in future research to explore how identities are constructed at different times and in different contexts by the same people. Furthermore, additional research into ELF interactions (in different contexts and regions) between interlocutors with varied English proficiency levels, involving follow-up interviews, would provide insights into the different strategies ELF speakers adopt to gain legitimacy, reach alignment and overcome challenges. This would help to identify what, if any, support ELF speakers might need to contribute to English language education in the era of globalization.

\section{References}

Alptekin, C., 2010. Redefining multicompetence for bilingualism and ELF. International Journal of Applied Linguistics 20, 95-110.

Anderson, K. T., 2009. Applying positioning theory to analysis of classroom interactions: Mediating micro-identities, macro-kinds, and ideologies of knowing. Linguistics and Education 20, 291-310.

Baker, W., 2009. The cultures of English as a Lingua Franca. TESOL Quarterly 43, 567592.

Baumgarten, N., House, J., 2010. I think and I don't know in English as lingua franca and native English discourse. Journal of Pragmatics 42, 1184-1200.

Björkman, B., 2008. English as the Lingua Franca of engineering: The morphosyntax of academic speech events. Nordic Journal of English Studies 7, 103-122.

Blommaert, J., 2005. Discourse: A Critical Introduction. Cambridge university press, Cambridge.

Bogden, R., Biklen, S., 2003. Qualitative Research for Education (4th ed.). Allyn Bacon, Boston.

Brinkmann, S., 2010. Guilt in a fluid culture: A view from positioning theory. Culture \& Psychology 16, 253-266.

Brutt-Griffler, J., 2002. Class, ethnicity, and language rights: An analysis of British colonial policy in Lesotho and Sri Lanka and some implications for language policy. Journal of Language, Identity, and Education 1, 207-234. 
Canagarajah, A. S., 2006a. Negotiating the local in English as a lingua franca. Annual Review of Applied Linguistics 26, 197-218.

Canagarajah, A. S., 2006b. The Place of World Englishes in Composition: Pluralization Continued. College Composition and Communication 57, 586-619.

Canagarajah, A. S., 2007. Lingua Franca English, multilingual communities, and language acquisition. Modern Language Journal 91, 923-39.

Cummins, J., 1996. Negotiating Identities: Education for Empowerment in a Diverse Society. California Association for Bilingual Education, Los Angeles.

Davies, C. E., 2004. Developing awareness of crosscultural pragmatics: The case of American/German sociable interaction. Multilingua 23, 207-231.

Davies, B., Harré, R., 1990. Positioning: The discursive production of selves. Journal for the Theory of Social Behavior 20, 43-63.

Fairclough, N., 2003. Analysing Discourse: Textual Analysis for Social Research. Routledge, London.

Harré, R., Moghaddam, F. M., 2003. Introduction: The self and others in traditional psychology and in positioning theory. In: Harré, R., Moghaddam, F.M. (Eds.), The Self and Others: Positioning Individuals and Groups in Personal, Political, and Cultural Contexts. Praeger, London, pp. 1-11.

Harré, R., Moghaddam, F. M., Cairnie, T. P., Rothbart, D., Sabat, S. R., 2009.

Recent advances in positioning theory. Theory Psychology, 19, 5-31.

Harré, R., van Langenhove, L., 1999. The dynamics of social episodes. In: Harré, R., van Langenhove, L. (Eds.), Positioning Theory: Moral Contexts of Intentional Action. Blackwell, Oxford, pp. 1-13.

House, J., 2003. English as a Lingua Franca: A threat to multilingualism? Journal of Sociolinguistics 7, 556-578.

House, J., 2009. Introduction: the pragmatics of English as a Lingua Franca. Intercultural Pragmatics 6, 141-145.

Ibrahim, A., 1999. Becoming black: Rap and hip-hop, race, gender, identity, and the politics of ESL learning. TESOL Quarterly 33, 349-369.

Jenkins, J., 2006. Current perspectives on teaching world Englishes and English as a Lingua Franca. TESOL Quarterly 40, 157-181.

Jenkins, J., 2007. English as a Lingua Franca: Attitude and Identity. Oxford University Press, Oxford.

Kachru, Braj B., (Ed.), 1992. The Other Tongue: English across Cultures (2nd edition). University of Illinois Press, Urbana.

Khubchandani, L. M., 1997. Revisualizing Boundaries: A Plurilingual Ethos. New Delhi, Sage, India.

Kirkpatrick, A., 2010a. Materials for the ELT Classroom in the Post-Anglophone Period. In: Widodo, H., Savova, L. (Eds.), Materials Design in English Language Teaching. Lincom Europa, Munich, pp. 135-146.

Kirkpatrick, A., 2010b. Researching English as a Lingua Franca in Asia: the Asian Corpus of English (ACE) project, Asian Englishes 31, 4-18.

Kirkpatrick, A., 2011. English as an Asian Lingua Franca and the Multilingual Model of ELT. Language Teaching 44, 212-224. 
Knapp, A., 2011. Using English as a lingua franca for (mis-)managing conflict in the international university: An example from a course in engineering. Journal of Pragmatics 43, 978-990.

Li, D., 2009. Researching NNSs' views toward intelligibility and identity: Bridging the gap between moral high grounds and down-to-earth concerns. In: Sharifian, F. (Ed.), English as an International Language: Perspectives and Pedagogical Issues. Multilingual Matters, Clevedon, pp. 81-118.

Linehan, C., McCarthy, J., 2000. Positioning in practice: Understanding participation in the social world. Journal for the Theory of Social Behavior 30, 435-453.

Louhiala-Salminen, L., Charles, M., Kankaanranta, A., 2005. English as a lingua franca in Nordic corporate mergers: Two case companies. English for Specific Purposes 24, 401-421.

Mauranen, A., 2003. The corpus of English as lingua franca in academic settings. TESOL Quarterly 37, 513-527.

Mauranen, A., 2006. Signalling and preventing misunderstanding in English as lingua franca communication. International Journal of the Sociology of Language 177, 123150.

Mauranen, A., Ranta, E., 2008. English as an academic lingua franca - the ELFA project. Nordic Journal of English Studies 7, 199-202.

McKay, S. L., 2002. Teaching English as an International Language. Oxford University Press, Oxford.

McKay, S. L., 2005. Sociolinguistics and second language learning. In: Hinkel, E. (Ed.), Handbook of Research in Second Language Teaching and Learning. Erlbaum, Mahwah, NJ, pp. 281-299.

Meierkord, C., 2004. Syntactic variation in interactions across international Englishes. English World-Wide 25, 109-132.

Omoniyi, T., 2006. Hierarchy of identities. In: Omoniyi, T., and White, G. (Eds.), The Sociolinguistics of Identity. Continuum, London, pp. 11-33.

Patton, M., 2002. Qualitative research and evaluation methods (3rd ed.). SAGE, Thousand Oaks, California.

Phillipson, R., 1992. Linguistic Imperialism. Oxford University Press, Oxford.

Planken, B., 2005. Managing rapport in lingua franca sales negotiations: A comparison of professional and aspiring negotiators. English for Specific Purposes 24, 381-400.

Rampton, B., 1995. Crossing: Language and Ethnicity among Adolescents. Longman, London.

Seidlhofer, B., 2004. Research perspectives on teaching English as a Lingua Franca. Annual Review of Applied Linguistics 24, 209-239.

Seidlhofer, B., 2005. English as a Lingua Franca. In: Hornby, A. S. (Ed.), Oxford Advanced Learner's Dictionary of Current English. (7th edition). Oxford University Press, Oxford, pp. R92.

Sung, C. C. M., 2013. Accent and identity: exploring the perceptions among bilingual speakers of English as a lingua franca in Hong Kong. International Journal of Bilingual Education and Bilingualism. doi: 10.1080/13670050.2013.837861.

Sung, C. C. M., 2014. Global, local or glocal? Identities of L2 learners in English as a Lingua Franca communication. Language, Culture and Curriculum 27, 43-57. van Langenhove, L., Harré, R., 1999. Positioning Theory. Blackwell, Oxford. 
Virkkula, T., Nikula, T., 2010. Identity construction in ELF contexts: A case study of Finnish engineering students working in Germany. International Journal of Applied Linguistics 20, 251-273.

Wood, L. A., Kroger, R. O., 2000. Doing Discourse Analysis. Sage, Thousand Oaks, California.

\section{Appendix}

Transcription conventions based on the Vienna Oxford International Corpus of English (VOICE)

(.) indicates a brief pause in the speech of up to a half second in duration; longer pauses are timed to the nearest second and marked with the number of seconds in parenthesis (e.g., (1) = 1 second, (3) = 3 seconds).

When two or more utterances are simultaneous, the overlaps are marked with numbered tags for each speaker: S1: $<1></ 1>$, S2: $<1></ 1>, \ldots$

Lengthened sounds are marked with a colon (:).

Laughter and laughter-like sounds are identified using the @ symbol, and the number of syllables approximated (e.g., ha-ha-ha=@@@).

If a corresponding existing word can be identified, that word is added between braces \{\} .

Words or abbreviations spelled out by the speaker - i.e., words whose constituent parts are pronounced as individual letters - are marked by <spel $>$.

Utterances spoken in a particular mode (fast, soft, read, etc.) notably different from the speaker's normal speaking style are marked accordingly (e.g., <fast>, <soft>, etc.).

Noticeable breathing in or out is represented by two or three h's (hh = relatively short; hhh = relatively long).

Names of places, cities, countries, etc. are omitted as needed to protect the speakers' identities and their environment, and are replaced by [place 1], etc. 